\title{
IMPLEMENTASI SIX SIGMA DALAM PENGENDALIAN KUALITAS PRODUK REFINED BLEACHED DEODORIZED PALM OIL
}

\author{
Anisa Rosyidasari*, Irwan Iftadi \\ Program Studi Teknik Industri, Fakultas Teknik, Universitas Sebelas Maret \\ Email: anisarosyidasari@student.uns.ac.id; iftadi@gmail.com
}

Artikel masuk : 21-07-2020

\author{
Artikel direvisi : 25-10-2020 \\ *Penulis Korespondensi
}

Artikel diterima : 05-11-2020

\begin{abstract}
Abstrak -- Sebagai perusahaan yang bergerak di bidang agribisnis pengolahan minyak goreng, PT $X Y Z$ mengalami permasalahan dalam produksi Refined Bleached Deodorized Palm Oil (RBDPO) yaitu tidak terpenuhinya spesifikasi produk. Tujuan dari penelitian ini adalah mengidentifikasi faktor utama penyebab terjadinya produk yang tidak memenuhi spesifikasi dan merekomendasikan alternatif usulan untuk mengurangi permasalahan tersebut. Berdasarkan perhitungan, didapatkan hasil RBDPO yang tidak memenuhi spesifikasi terjadi pada parameter nilai iodine value dan color dengan rata-rata Cpk sebesar 0,7355 dan sigma sebesar 3,7065. Nilai tersebut masih kurang baik karena belum mencapai target yaitu 6-Sigma. Untuk memaksimalkannya perlu dilakukan upaya perbaikan diantaranya melakukan seleksi pada bahan baku, melakukan pengawasan terhadap kinerja operator, melakukan maintenance mesin secara berkala, melakukan pencatatan terhadap perlakuan proses dan hasil sementara, serta melakukan pemeriksaan terhadap tangki penyimpanan.
\end{abstract}

Kata kunci: DMAIC; Kualitas; RBDPO; Six Sigma

\begin{abstract}
As a company engaged in cooking oil processing agribusiness, $P T X Y Z$ is experiencing problems in the production of Refined Bleached Deodorized Palm Oil (RBDPO), namely the failure to fulfill product specifications. This study aims to identify the main factors causing the occurrence of products that do not meet specifications and recommend alternative proposals to reduce these problems. Based on the calculation, the RBDPO results did not meet the specifications in the iodine value and color parameters with an average Cpk of 0.7355 and a sigma of 3.7065 . This value is still not good because it has not reached the target, namely 6-Sigma. Improvement efforts to increase the sigma value include selecting raw materials, supervising operator performance, performing periodic machine maintenance, recording process treatments, interim results, and checking storage tanks.
\end{abstract}

Keywords: DMAIC; Quality; RBDPO; Six Sigma

\section{PENDAHULUAN}

Kelapa sawit merupakan salah satu komoditas hasil perkebunan dan ekspor Indonesia yang cukup penting dalam perekonomian Indonesia (Badan Pusat Statistik, 2017). Sebagai negara penghasil minyak sawit terbesar di dunia, Indonesia pada tahun 2019 mampu memproduksi 51,828 juta ton minyak sawit dimana 47,18 ton yaitu Crude Palm Oil (CPO) dan 4,648 ton yaitu Palm Kernel Oil (PKO) (Gabungan Pengusaha Kelapa Sawit Indonesia, 2020). Seiring bertambahnya jumlah populasi yang ada di dunia, maka kebutuhan konsumsi mengenai berbagai macam produk cenderung meningkat. Hal ini tentunya juga berpengaruh pada permintaan minyak sawit sebagai bahan baku pembuatan produk pangan. Sehingga perusahaan dituntut untuk terus meningkatkan daya saing agar mampu menghasilkan produk dengan kualitas tinggi dan sesuai dengan preferensi konsumen.

PT XYZ merupakan salah satu perusahaan yang yang bergerak dalam industri agribisnis. Produk-produk yang dihasilkan yaitu minyak goreng dan margarin yang sekarang ini sudah tersebar di seluruh Indonesia hingga luar negeri. Produk minyak goreng PT XYZ menggunakan bahan baku utama Crude Palm Oil (CPO) yang berasal dari kelapa sawit. Proses produksi dan 
minyak goreng $\mathrm{PT} \mathrm{XYZ}$ adalah sistem kontinyu dan dilakukan dalam beberapa tahapan proses yaitu proses degumming (penghilangan getah), bleaching (pemucatan), dan deodorizing (penghilangan bau) yang menghasilkan produk setengah jadi yaitu Refined Bleached Deodorized Palm Oil (RBDPO). RBDPO kemudian dipisahkan menjadi RBDPO Olein untuk produk minyak goreng dan RBDPO Stearin untuk margarin melalui proses fraksinasi (Ulfah, 2012).

Sebagai perusahaan yang berfokus pada produk konsumen berbasis kelapa sawit, kualitas produksi menjadi hal penting bagi PT XYZ. Suatu produk dapat dikatakan berkualitas apabila mampu menunjang kemampuannya untuk memenuhi kebutuhan yang dispesifikasi (Gaspersz, 2005). Akan tetapi pada proses produksi minyak di PT XYZ masih terdapat produk yang out specs artinya tidak memenuhi spesifikasi yang diharapkan atau bisa dikatakan sebagai kualitas buruk sehingga menyebabkan minyak tersebut harus diolah kembali. Banyaknya minyak yang out specs dapat meningkatkan biaya dan waktu produksi yang besar (Ginting \& Ulkhaq, 2018). Hal ini tentunya dapat merugikan perusahaan. Oleh karena itu, perlu dilakukan perbaikan dan pengendalian kualitas agar dapat meminimasi produk out specs.

Salah satu cara untuk pengendalian kualitas suatu produk yaitu menggunakan metode Six Sigma dengan tahapan Define, Measure, Analyze, Improve, dan Control (DMAIC) (Sirine \& Kurniawati, 2017). Six Sigma adalah konsep statistik yang dapat meminimalkan cacat dan variasi hingga 3,4 defect per million opportunities (Valles et al., 2009). Six Sigma dapat dijadikan sebagai tolak ukur kinerja sistem industri, semakin tinggi nilai sigma yang dicapai maka kinerja sistem industri semakin baik (Lestari, 2020).

Penelitian-penelitian terkait dengan six sigma telah sukses diimplementasikan. Dalam pengelasan plate konstruksi baja berhasil meningkatkan nilai sigma semula 1,7 menjadi 2,1 (Rohimudin et al., 2016). Selain itu, dalam perusahaan home appliance mampu menurunkan defect sebesar 4,39\% (Ahmed et al., 2018). Tujuan dari penelitian ini adalah mengidentifikasi faktor utama penyebab terjadinya produk yang tidak memenuhi spesifikasi dan merekomendasikan alternatif usulan untuk mengurangi permasalahan tersebut.

\section{METODE PENELITIAN}

Data yang digunakan dalam penelitian ini diperoleh dari data primer dan data sekunder. Data primer didapatkan melalui observasi secara langsung di lapangan, wawancara, serta diskusi dengan operator di Departemen Refinery-
Fractionation. Sedangkan data sekunder diperoleh dari dokumen serta catatan perusahaan yang berhubungan dengan standar spesifikasi dan nilai parameter dari produk RBDPO. Tujuan dari dilakukannya observasi adalah untuk mempelajari proses yang ada dalam perusahaan. Tahap ini menekankan pada pengenalan dan pemahaman mengenai kondisi perusahaan dengan cara mengamati proses produksi dari awal hingga akhir dan memastikannya dengan cara wawancara secara langsung kepada operator dan kepala divisi. Metode penelitian ini menggunakan pendekatan Six Sigma dengan tahapan Define, Measure, Analyze, Improve, dan Control (DMAIC).

\section{Tahap Define}

Tahap ini bertujuan untuk mendefinisikan masalah pada proses atau produk. Dalam tahap ini dilakukan mengidentifikasi karakteristik kualitas atau CTQ dan mengidentifikasi proses dengan diagram SIPOC (Supplier-Input-Process-OutputCustomer) (Stern, 2016). Diagram SIPOC merupakan suatu tools yang menggambarkan proses produksi dari awal hingga akhir sehingga dapat memudahkan identifikasi masalah (Pangestu \& Fahma, 2019).

\section{Tahap Measure}

Tahap ini bertujuan untuk mengukur standar kinerja proses dalam menghasilkan produk. Dalam tahap ini dilakukan pengukuran stabilitas proses menggunakan peta kendali untuk menentukan parameter mana yang mengalami out specs, perhitungan nilai DPMO data variabel, perhitungan nilai sigma yang didapat dari tabel konversi nilai DPMO ke dalam tingkatan sigma, dan pengukuran kapabilitas proses.

$$
\begin{aligned}
& D P M O=\mathrm{P}\left[\mathrm{Z} \geq\left(\frac{\mathrm{USL}-\overline{\mathrm{x}}}{\mathrm{S}}\right)\right] \times 100000+\mathrm{P}\left[\mathrm{Z} \leq\left(\frac{\mathrm{LSL}-\overline{\mathrm{X}}}{\mathrm{S}}\right)\right] \times 1000000 \\
& \text { Sigma }=\text { normsinv }\left[1-\left(\frac{\mathrm{DPMO}}{1.000 .000}\right)\right]+1,5 \\
& C p k=\operatorname{Min}\left(\frac{\mathrm{USL}-\overline{\mathrm{X}}}{3 \sigma}\right),\left(\frac{\overline{\mathrm{X}}-\mathrm{LSL}}{3 \sigma}\right)
\end{aligned}
$$

\section{Tahap Analyze}

Tahap ini bertujuan untuk mengidentifikasi penyebab permasalahan. Dalam tahap ini dilakukan pembuatan pareto chart untuk menganalisis out specs paling dominan dan fishbone diagram untuk menganalisis penyebab terjadinya out specs. Secara umum, dalam fishbone diagram terdapat kategori sebagai berikut (Yuanita, 2018) :

1. Man, sumber daya manusia yang terlibat dalam proses produksi. 
2. Method, bagaimana proses dilaksanakan dan persyaratan apa saja yang dibutuhkan untuk melaksanakan proses produksi.

3. Material, yaitu bahan mentah, bahan baku, dan bahan-bahan lainnya yang digunakan sebagai input proses produksi.

4. Machine, peralatan yang digunakan sebagai proses produksi.

5. Environment, yaitu kondisi seperti lokasi, waktu, dan suhu saat proses produksi.

\section{Tahap Improve}

Tahap ini bertujuan untuk merencanakan tindakan perbaikan pada proses produksi RBDPO agar mencapai standar yang diharapkan. Dalam tahap ini dilakukan pembuatan Failure Mode and Effect Analysis (FMEA) dengan menghitung nilai Risk Priority Number (RPN). Nilai RPN tertinggi akan menjadi prioritas untuk usulan tindakan perbaikan (Manan et al., 2018).

$R P N=$ occurance $x$ severty $x$ detection

\section{Tahap Control}

Tahap ini merupakan tahapan six sigma terakhir dalam perbaikan pengendalian kualitas (Fithri, 2019). Tahap ini bertujuan untuk mengendalikan perbaikan-perbaikan yang telah dibuat pada tahap improve. Selain itu, mengontrolnya agar masalah yang sama tidak terulang kembali.

\section{HASIL DAN PEMBAHASAN}

Data yang digunakan dalam penelitian ini adalah data variabel produk RBDPO berdasarkan parameter nilai lodine Value (IV), Free Fatty Acid (FFA), Peroxide Value (PV) serta color selama bulan Desember 2019 hingga Januari 2020. Dari data tersebut masih ditemukan produk out specs artinya tidak memenuhi spesifikasi yang diharapkan. Untuk menyelesaikan masalah terjadinya out specs, penelitian dilakukan melalui lima tahapan yaitu define, measure, analyze, improve, dan control.

\section{Tahap Define}

Pada tahap ini dilakukan identifikasi masalah terhadap proses menggunakan diagram SIPOC dan produk menggunakan CTQ. Diagram SIPOC (Tabel 1) menggambarkan proses produksi RBDPO mulai awal hingga akhir. Refined Bleached Deodorized Palm Oil (RBDPO) terbuat dari bahan baku utama Crude Palm Oil (CPO) yang didapat dari perkebunan sawit milik perusahaan dan bahan tambahan berupa Phosphoric Acid (PA) dan Bleaching Earth (BE) yang diimpor dari Cina ataupun Jepang. Bahan tersebut kemudian diolah melalui tahapan degumming yang menghasilkan Degummed Palm Oil (DPO), tahapan bleaching menghasilkan Degummed Bleached Palm Oil (DBPO), tahapan filtrasi menghasilkan DBPO dan spenth earth, tahapan deodorizing menghasilkan produk akhir berupa RBDPO dan produk sampingan Palm Fatty Acid Distillate (PFAD).

Tabel 1. Diagram SIPOC Produksi RBDPO

\begin{tabular}{|c|c|c|c|c|}
\hline Supplier & Input & Process & Output & $\begin{array}{c}\text { Custo- } \\
\text { mer }\end{array}$ \\
\hline $\begin{array}{l}\text { CPO: } \\
\text { Perkebunan } \\
\text { kelapa sawit }\end{array}$ & CPO & Setting & & \\
\hline PA : Cina & $\begin{array}{c}\text { CPO, } \\
\text { PA }\end{array}$ & Degumming & DPO & \\
\hline \multirow[t]{3}{*}{$\begin{array}{l}\text { BE : Cina } \\
\text { Dan Jepang }\end{array}$} & $\begin{array}{c}\text { DPO, } \\
\text { BE }\end{array}$ & Bleaching & DBPO & \\
\hline & & Filtration & $\begin{array}{l}\text { DBPO, } \\
\text { spent } \\
\text { earth }\end{array}$ & \\
\hline & & Deodorizing & $\begin{array}{c}\text { RBDPO, } \\
\text { PFAD }\end{array}$ & $\begin{array}{c}\text { Fracti- } \\
\text { nation } \\
\text { Plant }\end{array}$ \\
\hline
\end{tabular}

CTQ digambarkan untuk mengetahui karakteristik kualitas produk agar mencapai standar spesifikasi. CTQ RBDPO (Gambar 1) ditentukan berdasarkan parameter nilai iodine value (IV), free fatty acid (FFA), peroxide value (PV), serta color. lodine value digunakan untuk menentukan ketidakjenuhan minyak, minyak dengan IV rendah berwujud padat sedangkan IV tinggi berwujud cair. Kadar FFA berfungsi untuk mengetahui kandungan asam lemak bebas. Nilai PV merupakan nilai yang menyatakan tingkat kerusakan primer minyak, semakin tinggi nilai PV suatu minyak akan menyebabkan semakin mudah tengik. Color yaitu pengujian warna dari minyak goreng (Luthfian Ramadhan Silalahi et al., 2017). Standar kualitas RBDPO PT XYZ yang baik apabila nilai IV minimal $52,00 \mathrm{gr} / \mathrm{l}_{2} 100 \mathrm{gr}$; nilai FFA maksimal $0,05 \%$ as palmitic; nilai PV maksimal 1,00 meq $\mathrm{O}_{2} / \mathrm{kg}$; serta nilai color red maksimal 1,50 .

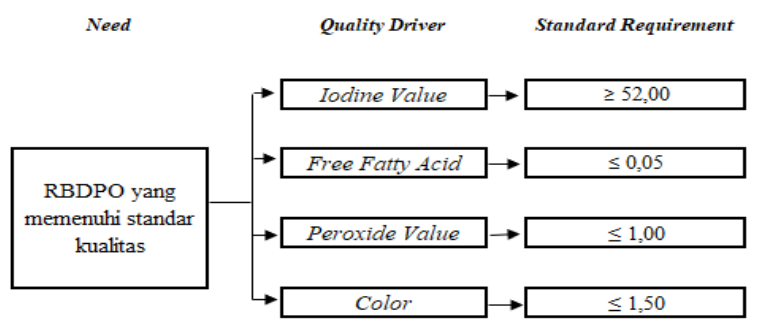

Gambar 1. CTQ RBDPO 


\section{Tahap Measure}

Pada tahap ini dilakukan pengukuran stabilitas proses menggunakan peta kendali, perhitungan nilai DPMO, nilai sigma, dan kapabilitas proses. Pengukuran stabilitas proses dimulai dengan menentukan USL dan LSL dari setiap parameter kualitas RBDPO yang sudah ditentukan oleh PT XYZ (Tabel 2). Produk mengalami out specs apabila setiap parameter berada di bawah LSL maupun USL. Berdasarkan grafik peta kendali yang ditunjukkan pada Gambar 2 dapat diketahui bahwa proses tidak terkendali terjadi pada parameter IV dan color. Oleh karena itu parameter IV dan color dilakukan perhitungan nilai DPMO, nilai sigma, dan kapabilitas proses.

Tabel 2. Nilai USL dan LSL Parameter Kualitas $R B D P O$

\begin{tabular}{ccc}
\hline Parameter & USL & LSL \\
\hline lodine Value (IV) & 54 & 52 \\
Peroxide Value (PV) & 1 & 0 \\
Free Fatty Acid (FFA) & 0,05 & 0 \\
Color & 1,5 & 0 \\
\hline
\end{tabular}

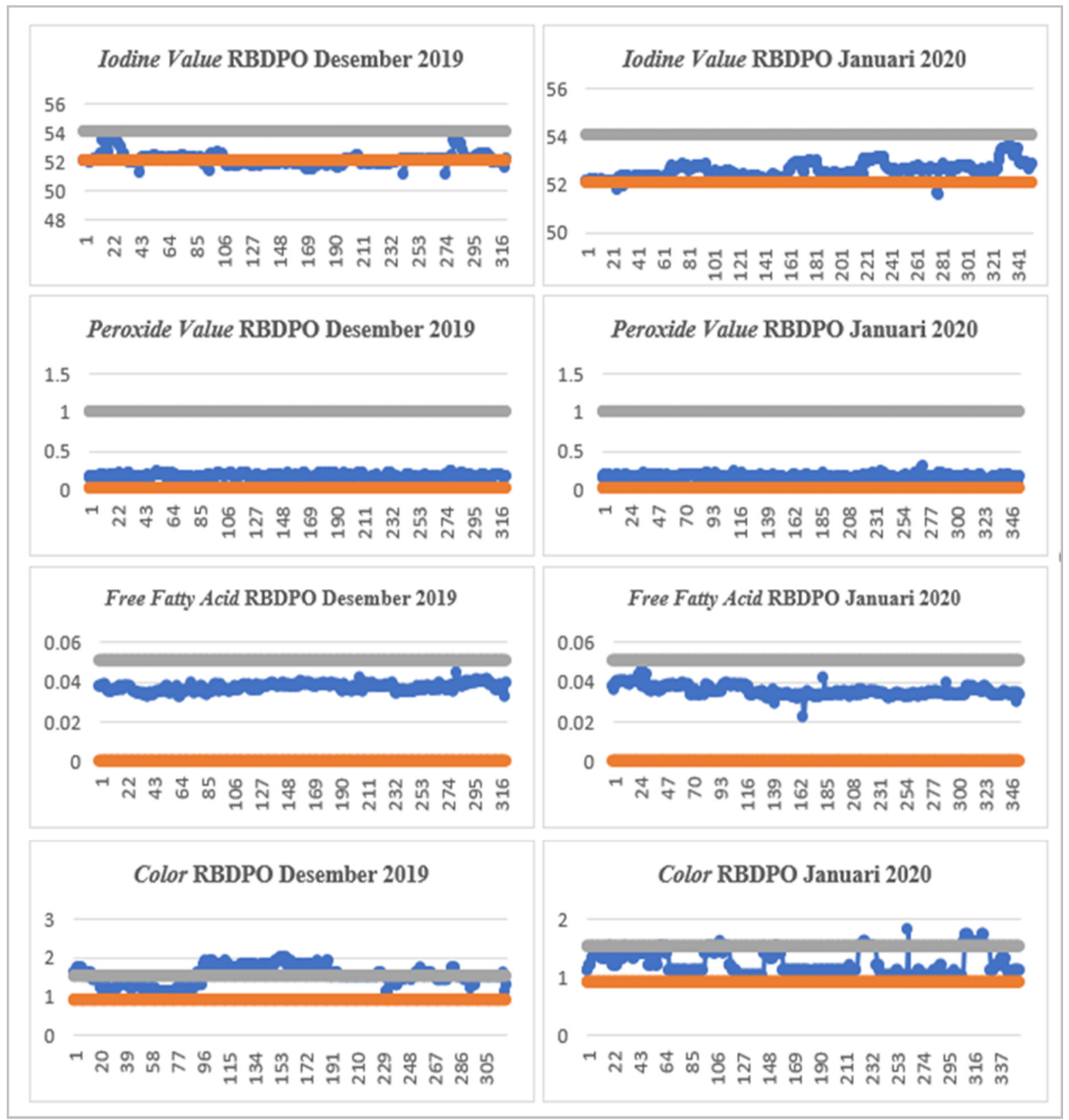

Gambar 2. Grafik Nilai Parameter RBDPO Bulan Desember 2019 dan Januari 2020 
Langkah selanjutnya adalah melakukan perhitungan nilai DPMO dan nilai sigma dari masing-masing parameter. Nilai DPMO dan nilai sigma merupakan suatu nilai yang digunakan untuk menunjukkan kemampuan proses dan dapat dijadikan sebagai tolak ukur untuk melakukan upaya perbaikan. Perhitungan nilai DPMO dan nilai pada data variabel iodine value dan color menggunakan pemilihan enam sampel secara acak. Langkah awal dalam menghitung nilai sigma adalah menghitung rata-rata, range, dan standar deviasi yang ditunjukkan dalam Tabel 3 untuk parameter iodine value dan Tabel 4 untuk parameter color.

i. Parameter lodine Value

Rata-rata proses:

$$
\bar{x}=\frac{\sum \bar{x}}{N}=\frac{2982,3800}{58}=52,3225
$$

\section{Range:}

$\bar{R}=\frac{\sum \bar{R}}{N}=\frac{21,0200}{58}=0,3688$

Standar Deviasi: (berdasarkan tabel untuk $\mathrm{n}=6$, nilai $\mathrm{d}_{2}=2,534$ )

$S=\frac{\bar{R}}{\mathrm{~d} 2}=\frac{0,3688}{2,534}=0,1455$

ii. Parameter Color

$\bar{x}=\frac{\sum \bar{x}}{N}=\frac{78,6500}{58}=1,3798$

Range:

$$
\bar{R}=\frac{\sum \bar{R}}{N}=\frac{7,900}{58}=0,1386
$$

Standar Deviasi: (berdasarkan tabel untuk $\mathrm{n}=6$, nilai $\mathrm{d}_{2}=2,534$ )

$S=\frac{\bar{R}}{\mathrm{~d} 2}=\frac{0,1386}{2,534}=0,0547$

\begin{tabular}{|c|c|c|c|c|c|c|c|c|c|}
\hline \multirow{2}{*}{ Tanggal } & \multicolumn{6}{|c|}{ Batch } & \multirow[b]{2}{*}{$X$} & \multirow{2}{*}{$R$} & \multirow{2}{*}{$S$} \\
\hline & 1 & 2 & 3 & 4 & 5 & 6 & & & \\
\hline $01 / 12 / 2019$ & 51,98 & 51,97 & 52,01 & 51,97 & 51,93 & 51,92 & 51,96 & 0,09 & 0,0355 \\
\hline $02 / 12 / 2019$ & 52,07 & 52,09 & 52,50 & 53,46 & 53,42 & 53,55 & 52,85 & 1,48 & 0,5841 \\
\hline $03 / 12 / 2019$ & 53,36 & 53,42 & 53,45 & 53,46 & 53,43 & 53,48 & 53,43 & 0,12 & 0,0474 \\
\hline $04 / 12 / 2019$ & 51,94 & 51,90 & 51,93 & 51,97 & 51,98 & 51,91 & 51,94 & 0,08 & 0,0316 \\
\hline 05/12/2019 & 52,25 & 52,30 & 52,30 & 52,27 & 52,29 & 52,29 & 52,28 & 0,05 & 0,0197 \\
\hline $06 / 12 / 2019$ & 52,16 & 52,22 & 52,36 & 52,32 & 52,23 & 52,22 & 52,25 & 0,2 & 0,0789 \\
\hline $07 / 12 / 2019$ & 52,08 & 52,03 & 51,97 & 52,17 & 52,21 & 52,27 & 52,12 & 0,3 & 0,1184 \\
\hline $08 / 12 / 2019$ & 51,96 & 52,18 & 52,34 & 52,41 & 52,12 & 52,06 & 52,18 & 0,45 & 0,1776 \\
\hline 09/12/2019 & 52,22 & 52,17 & 52,22 & 52,14 & 52,14 & 52,14 & 52,17 & 0,08 & 0,0316 \\
\hline 11/12/2019 & 52,41 & 52,44 & 52,45 & 52,34 & 52,46 & 52,45 & 52,43 & 0,12 & 0,0474 \\
\hline $12 / 12 / 2019$ & 51,78 & 51,69 & 51,75 & 51,74 & 51,76 & 51,64 & 51,73 & 0,14 & 0,0552 \\
\hline $14 / 12 / 2019$ & 51,72 & 51,68 & 51,72 & 51,73 & 51,75 & 51,74 & 51,72 & 0,07 & 0,0276 \\
\hline $15 / 12 / 2019$ & 51,87 & 51,84 & 51,83 & 51,88 & 51,85 & 51,92 & 51,87 & 0,09 & 0,0355 \\
\hline $16 / 12 / 2019$ & 51,92 & 51,85 & 51,87 & 51,79 & 51,87 & 51,91 & 51,87 & 0,13 & 0,0513 \\
\hline $17 / 12 / 2019$ & 51,89 & 51,83 & 51,80 & 51,82 & 51,81 & 51,83 & 51,83 & 0,09 & 0,0355 \\
\hline $18 / 12 / 2019$ & 51,55 & 51,42 & 51,53 & 51,45 & 51,48 & 51,52 & 51,49 & 0,13 & 0,0513 \\
\hline$\cdots$ & $\ldots$ & & & $\ldots$ & $\cdots$ & & $\cdots$ & $\ldots$ & $\ldots$ \\
\hline $14 / 01 / 2020$ & 52,13 & 52,10 & 52,23 & 52,22 & 52,23 & 52,27 & 52,20 & 0,17 & 0,0671 \\
\hline $15 / 01 / 2020$ & 52,85 & 52,74 & 52,85 & 52,91 & 52,55 & 52,49 & 52,73 & 0,42 & 0,1657 \\
\hline $16 / 01 / 2020$ & 61,50 & 52,81 & 52,56 & 52,52 & 52,37 & 52,40 & 54,03 & 9,13 & 3,6030 \\
\hline $17 / 01 / 2020$ & 52,38 & 52,37 & 52,43 & 52,43 & 52,31 & 52,34 & 52,38 & 0,12 & 0,0474 \\
\hline $18 / 01 / 2020$ & 52,43 & 52,40 & 52,33 & 52,36 & 52,44 & 52,29 & 52,38 & 0,15 & 0,0592 \\
\hline $19 / 01 / 2020$ & 53,00 & 52,80 & 52,91 & 53,01 & 52,97 & 52,97 & 52,94 & 0,21 & 0,0829 \\
\hline $20 / 01 / 2020$ & 53,06 & 53,05 & 52,76 & 52,69 & 52,61 & 52,57 & 52,79 & 0,49 & 0,1934 \\
\hline $21 / 01 / 2020$ & 52,59 & 52,58 & 52,58 & 52,60 & 52,53 & 52,50 & 52,56 & 0,1 & 0,0395 \\
\hline $24 / 01 / 2020$ & 52,62 & 52,66 & 52,53 & 52,55 & 52,58 & 52,62 & 52,59 & 0,13 & 0,0513 \\
\hline $25 / 01 / 2020$ & 52,63 & 52,57 & 52,52 & 52,65 & 52,62 & 52,61 & 52,60 & 0,13 & 0,0513 \\
\hline $26 / 01 / 2020$ & 52,78 & 52,65 & 52,61 & 52,59 & 52,61 & 52,64 & 52,65 & 0,19 & 0,0750 \\
\hline $27 / 01 / 2020$ & 52,73 & 52,75 & 52,77 & 52,71 & 52,74 & 52,70 & 52,73 & 0,07 & 0,0276 \\
\hline $28 / 01 / 2020$ & 52,48 & 52,51 & 52,57 & 52,50 & 52,45 & 52,52 & 52,51 & 0,12 & 0,0474 \\
\hline $29 / 01 / 2020$ & 52,45 & 52,51 & 52,46 & 52,59 & 52,62 & 52,94 & 52,60 & 0,49 & 0,1934 \\
\hline $30 / 01 / 2020$ & 53,46 & 53,50 & 53,48 & 53,19 & 53,24 & 53,45 & 53,39 & 0,31 & 0,1223 \\
\hline $31 / 01 / 2020$ & 52,88 & 52,83 & 52,82 & 52,60 & 52,73 & 52,78 & 52,77 & 0,28 & 0,1105 \\
\hline \multirow{2}{*}{\multicolumn{7}{|c|}{$\begin{array}{c}\text { Jumlah } \\
\text { Rata-rata }\end{array}$}} & 2982,38 & 21,02 & 8,2952 \\
\hline & & & & & & & 52,3225 & 0,3688 & 0,1455 \\
\hline
\end{tabular}

Tabel 3. Pengolahan Data Variabel lodine Value 
Tabel 4. Pengolahan Data Variabel Color

\begin{tabular}{|c|c|c|c|c|c|c|c|c|c|}
\hline \multirow{2}{*}{ Tanggal } & \multicolumn{6}{|c|}{ Batch } & \multirow{2}{*}{$\bar{X}$} & \multirow[b]{2}{*}{$R$} & \multirow{2}{*}{$S$} \\
\hline & 1 & 2 & 3 & 4 & 5 & 6 & & & \\
\hline $01 / 12 / 2019$ & 1,6 & 1,6 & $\overline{1,6}$ & 1,7 & 1,7 & 1,7 & 1,6500 & 0,1000 & 0,0395 \\
\hline $02 / 12 / 2019$ & 1,6 & 1,6 & 1,6 & 1,4 & 1,4 & 1,4 & 1,5000 & 0,2000 & 0,0789 \\
\hline 03/12/2019 & 1,2 & 1,2 & 1,3 & 1,4 & 1,5 & 1,5 & 1,3500 & 0,3000 & 0,1184 \\
\hline $04 / 12 / 2019$ & 1,3 & 1,3 & 1,4 & 1,4 & 1,3 & 1,3 & 1,3333 & 0,1000 & 0,0395 \\
\hline $05 / 12 / 2019$ & 1,3 & 1,3 & 1,3 & 1,3 & 1,3 & 1,2 & 1,2833 & 0,1000 & 0,0395 \\
\hline 06/12/2019 & 1,2 & 1,2 & 1,2 & 1,2 & 1,1 & 1,1 & 1,1667 & 0,1000 & 0,0395 \\
\hline 07/12/2019 & 1,1 & 1,1 & 1,1 & 1,1 & 1,1 & 1,1 & 1,1000 & 0,0000 & 0,0000 \\
\hline 08/12/2019 & 1,1 & 1,1 & 1,1 & 1,1 & 1,1 & 1,2 & 1,1167 & 0,1000 & 0,0395 \\
\hline 09/12/2019 & 1,1 & 1,1 & 1,4 & 1,1 & 1,3 & 1,2 & 1,2000 & 0,3000 & 0,1184 \\
\hline $11 / 12 / 2019$ & 1,8 & 1,8 & 1,9 & 1,6 & 1,6 & 1,9 & 1,7667 & 0,3000 & 0,1184 \\
\hline$\cdots$ & $\cdots$ & $\cdots$ & $\cdots$ & $\cdots$ & $\cdots$ & $\cdots$ & $\cdots$ & $\ldots$ & $\ldots$ \\
\hline $20 / 01 / 2020$ & 1,2 & 1,2 & 1,1 & 1,2 & 1 & 1 & 1,1167 & 0,2000 & 0,0789 \\
\hline $21 / 01 / 2020$ & 1 & 1 & 1,1 & 1,1 & 1 & 1 & 1,0333 & 0,1000 & 0,0395 \\
\hline $24 / 01 / 2020$ & 1 & 1 & 0,9 & 0,9 & 1 & 1 & 0,9667 & 0,1000 & 0,0395 \\
\hline $25 / 01 / 2020$ & 1,1 & 1,1 & 1,1 & 1 & 1 & 1 & 1,0500 & 0,1000 & 0,0395 \\
\hline $26 / 01 / 2020$ & 1,1 & 1,1 & 1,1 & 1,1 & 1,1 & 1,2 & 1,1167 & 0,1000 & 0,0395 \\
\hline $27 / 01 / 2020$ & 1 & 1 & 1 & 1,1 & 1 & 1 & 1,0167 & 0,1000 & 0,0395 \\
\hline $28 / 01 / 2020$ & 1,6 & 1,6 & 1,6 & 1,6 & 1,6 & 1,5 & 1,5833 & 0,1000 & 0,0395 \\
\hline $29 / 01 / 2020$ & 1,7 & 1,7 & 1,7 & 1,5 & 1,5 & 1,5 & 1,6000 & 0,2000 & 0,0789 \\
\hline $30 / 01 / 2020$ & 1,2 & 1,2 & 1,3 & 1,3 & 1,3 & 1,3 & 1,2667 & 0,1000 & 0,0395 \\
\hline $31 / 01 / 2020$ & 1,1 & 1,1 & 1,1 & 1,1 & 1,1 & 1,1 & 1,1000 & 0,0000 & 0,0000 \\
\hline \multicolumn{7}{|c|}{ Jumlah } & 78,6500 & 7,9000 & 3,1176 \\
\hline \multicolumn{7}{|c|}{ Rata-rata } & 1,3798 & 0,1386 & 0,0547 \\
\hline
\end{tabular}

Adapun perhitungan nilai DPMO dan nilai sigma adalah sebagai berikut:

Perhitungan proses keseluruhan iodine value

i. DPMO Nilai USL

$$
\begin{aligned}
& =\mathrm{P}\left[\mathrm{Z} \geq\left(\frac{\mathrm{USL}-\overline{\mathrm{X}}}{\mathrm{S}}\right)\right] \times 1000000 \\
& =\mathrm{P}\left[\mathrm{Z} \geq\left(\frac{54-52,3225}{0,1455}\right)\right] \times 1000000 \\
& =\mathrm{P}[\mathrm{Z} \geq 11,5272] \times 1000000 \\
& =(1-\mathrm{P}[\mathrm{Z} \leq 11,5272]) \times 1000000 \\
& =(1-1) \times 1000000 \\
& =0
\end{aligned}
$$

ii. DPMO Nilai LSL

$$
\begin{aligned}
& =\mathrm{P}\left[\mathrm{Z} \leq\left(\frac{\mathrm{LSL}-\overline{\mathrm{X}}}{\mathrm{S}}\right)\right] \times 1000000 \\
& =\mathrm{P}\left[\mathrm{Z} \leq\left(\frac{52-52,3225}{0,1455}\right)\right] \times 1000000 \\
& =\mathrm{P}[\mathrm{Z} \leq-2,2157] \times 1000000 \\
& =0,0133545 \times 1000000 \\
& =13355
\end{aligned}
$$

iii. DPMO Total

$$
=0+13355
$$$$
=13355
$$

iv. Nilai Sigma (dari tabel konversi DPMO) $=3,7157$

v. $\mathrm{C}_{\mathrm{pk}}$

$$
\begin{aligned}
& =\operatorname{Min}\left(\frac{\mathrm{USL}-\overline{\mathrm{X}}}{3 \sigma}\right),\left(\frac{\overline{\mathrm{X}}-\mathrm{LSL}}{3 \sigma}\right) \\
& =\operatorname{Min}\left(\frac{54-52,3225}{3(0,1455)}\right),\left(\frac{52,3225-52}{3(0,1455)}\right)
\end{aligned}
$$

$$
\begin{aligned}
& =\operatorname{Min}(3,8424),(0,7386) \\
& =0,7386
\end{aligned}
$$

Perhitungan proses keseluruhan color:

i. DPMO Nilai USL

$$
\begin{aligned}
& =\mathrm{P}\left[\mathrm{Z} \geq\left(\frac{\mathrm{USL}-\overline{\mathrm{X}}}{\mathrm{S}}\right)\right] \times 1000000 \\
& =\mathrm{P}\left[\mathrm{Z} \geq\left(\frac{1,5-1,3798}{0,0547}\right)\right] \times 1000000 \\
& =\mathrm{P}[\mathrm{Z} \geq 2,1972] \times 1000000 \\
& =(1-\mathrm{P}[\mathrm{Z} \leq 2,1972]) \times 1000000 \\
& =(1-0,985997) \times 1000000 \\
& =14003
\end{aligned}
$$

ii. DPMO Nilai LSL

$$
\begin{aligned}
& =\mathrm{P}\left[\mathrm{Z} \leq\left(\frac{\mathrm{LSL}-\overline{\mathrm{X}}}{\mathrm{S}}\right)\right] \times 1000000 \\
& =\mathrm{P}\left[\mathrm{Z} \leq\left(\frac{0-1,3798}{0,0547}\right)\right] \times 1000000 \\
& =\mathrm{P}[\mathrm{Z} \leq-25,2277] \times 1000000 \\
& =0 \times 1000000
\end{aligned}
$$

$$
=0
$$

iii. DPMO Total

$$
=14003+0
$$

$$
=14003
$$

iv. Nilai Sigma (dari tabel konversi DPMO)

$$
=3,6972
$$

v. Cpk

$$
=\operatorname{Min}\left(\frac{\mathrm{USL}-\overline{\mathrm{X}}}{3 \sigma}\right),\left(\frac{\overline{\mathrm{X}}-\mathrm{LSL}}{3 \sigma}\right)
$$




$$
\begin{aligned}
& =\operatorname{Min}\left(\frac{1,5-1,3798}{3(0,0547)}\right),\left(\frac{1,3798-0}{3(0,0547)}\right) \\
& =\operatorname{Min}(0,7324),(8,4092) \\
& =0,7324
\end{aligned}
$$

Rata-rata Sigma

$$
=\frac{(3,7157+3,6972)}{2}
$$

Rata-rata Cpk

$$
\begin{aligned}
& =\frac{(3,7157+3,6972)}{2} \\
& =0,7355
\end{aligned}
$$

Berdasarkan perhitungan dapat diketahui bahwa nilai sigma yang diperoleh pada parameter iodine value dan color berturut-turut sebesar 3,7157 dan 3,6972 sehingga rata-rata nilai sigma sebesar 3,7065 artinya rata-rata industri Indonesia sedangkan nilai Cpk yang diperoleh sebesar 0,7386 dan 0,7324 sehingga rata rata nilai Cpk sebesar 0,7355 dimana terletak dalam rentang $0,5 \leq \mathrm{Cpk} \leq 1,5$ artinya proses dianggap cukup mampu namun perlu upaya untuk meningkatkan kualitas agar menuju target yang diinginkan.

\section{Tahap Analyze}

Pada tahap ini dilakukan pembuatan pareto chart dan fishbone diagram. Pareto chart berfungsi untuk menganalisis out specs paling dominan sedangkan fishbone diagram untuk menganalisis penyebab terjadinya out specs. Berdasarkan diagram pareto pada Gambar 3 dapat diketahui bahwa out specs paling dominan yang terjadi pada bulan Desember 2019 sampai Januari 2020 adalah iodine value sebanyak 163 kali (52\%) dan color sebanyak 149 kali (48\%).

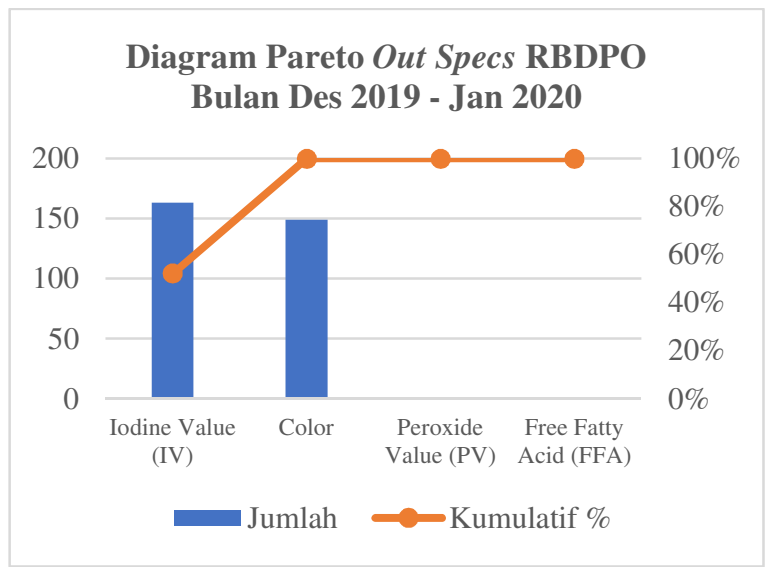

Gambar 3. Diagram Pareto Out Specs RBDPO

Penyebab terjadinya out specs dapat dilihat dari berbagai faktor melalui fishbone diagram pada Gambar 4 dan Gambar 5. Faktor manusia, karena kurangnya ketelitian dan ketanggapan dari operator. Faktor bahan, karena kualitas bahan baku berupa CPO dan bahan tambahan BE yang buruk. Faktor mesin, karena kinerjanya yang kurang maksimal akibat tidak dilakukan maintenance secara berkala. Faktor metode, karena perlakuan pada proses yang tidak sesuai. Faktor lingkungan, karena tangki penyimpanan yang terkontaminasi.

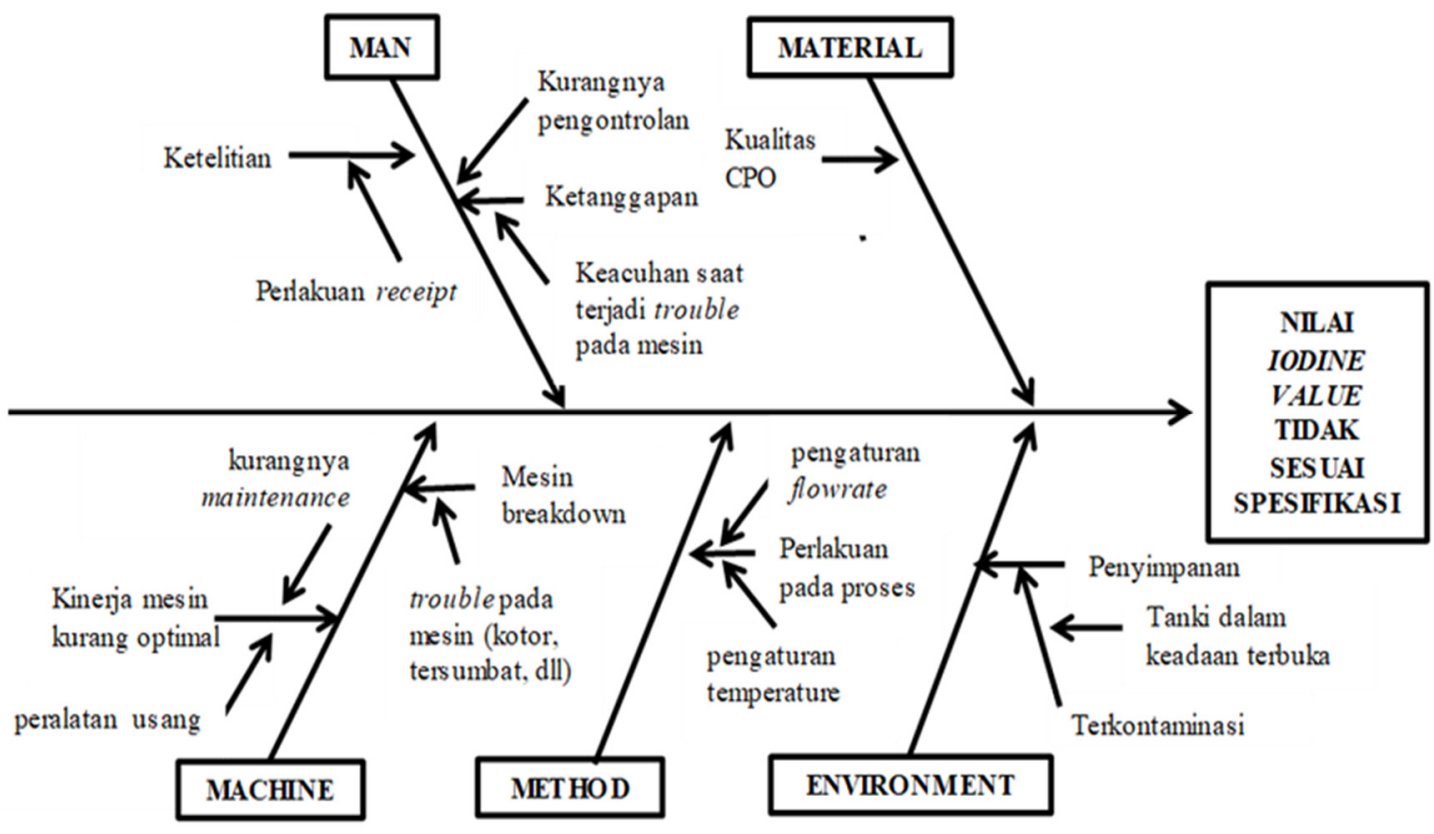

Gambar 4. Fishbone Diagram Nilai Lodine Value 


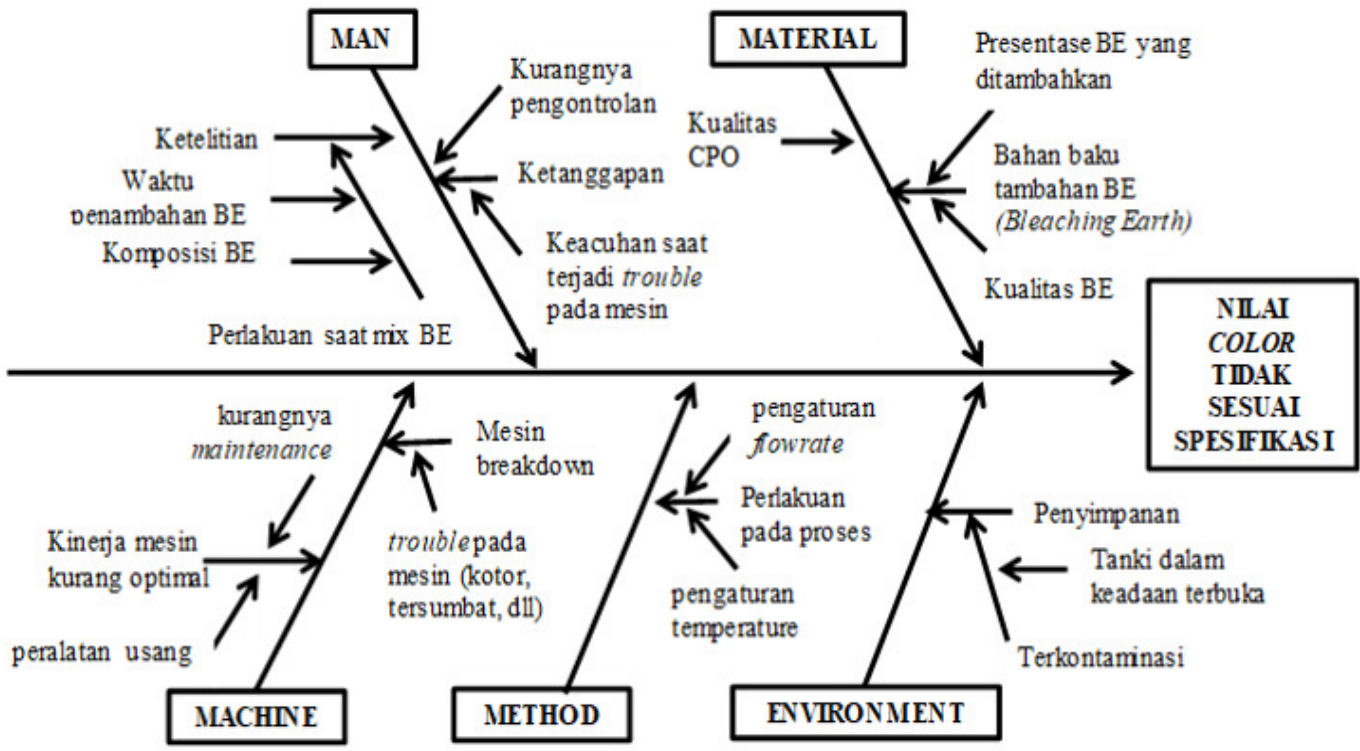

Gambar 5. Fishbone Diagram Nilai Color

\section{Tahap Improve}

Pada tahap ini dilakukan upaya perbaikan menggunakan metode Failure Mode Effect and Analysis (FMEA). FMEA merupakan tools untuk mengidentifikasi dan menilai risiko potensial kegagalan yang dapat menjadi pertimbangan sebagai prioritas tindakan perbaikan. Penilaian risiko dilakukan dengan mengalikan nilai pada masing-masing faktor yaitu severity, occurrence, dan detection sehingga didapatkan RPN (Kubiak \& Benbow, 2016).

Berdasarkan perhitungan pada Tabel 5, nilai RPN tertinggi sebesar 392 pada kegagalan nilai IV dan 343 pada kegagalan nilai color. Penyebab kegagalan keduanya yaitu kualitas CPO yang buruk. Usulan perbaikan yang dapat dilakukan adalah melakukan seleksi terhadap kualitas CPO.

Tabel 5. Failure Mode Effect Analysis

\begin{tabular}{|c|c|c|c|c|c|c|c|c|}
\hline $\begin{array}{c}\text { Mode } \\
\text { Kegagalan }\end{array}$ & $\begin{array}{c}\text { Efek } \\
\text { Kegagalan }\end{array}$ & $\mathbf{S}$ & Penyebab Kegagalan & 0 & D & RPN & Rank & Tindakan Perbaikan \\
\hline \multirow{5}{*}{$\begin{array}{l}\text { Nilai IV } \\
\text { rendah } \\
\text { (tidak sesuai } \\
\text { spesifikasi) }\end{array}$} & \multirow{5}{*}{$\begin{array}{l}\text { RBDPO berkualitas } \\
\text { rendah dengan sifat } \\
\text { kental dan pekat }\end{array}$} & & $\begin{array}{l}\text { Operator yang tidak teliti } \\
\text { dan tidak tanggap dalam } \\
\text { melakukan pekerjaan }\end{array}$ & 4 & 6 & 192 & 2 & $\begin{array}{l}\text { Melakukan pengawasan } \\
\text { intensif terhadap kinerja } \\
\text { operator dan memberi } \\
\text { reward dan punishment } \\
\text { sesuai kinerja karyawan }\end{array}$ \\
\hline & & & $\begin{array}{l}\text { Kualitas CPO yang } \\
\text { diterima buruk akibat } \\
\text { proses pemanenan dan } \\
\text { pengolahan kelapa sawit } \\
\text { yang tidak tepat }\end{array}$ & 7 & 7 & 392 & 1 & 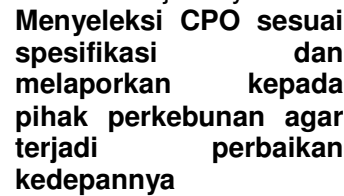 \\
\hline & & & $\begin{array}{l}\text { Kinerja mesin kurang } \\
\text { optimal akibat penggunaan } \\
\text { secara terus-menerus yang } \\
\text { tidak diimbangi dengan } \\
\text { perawatan }\end{array}$ & 4 & 4 & 128 & 4 & $\begin{array}{l}\text { Pemeriksaan mesin } \\
\text { secara berkala, apabila } \\
\text { terdapat kerusakan segera } \\
\text { diperbaiki }\end{array}$ \\
\hline & & & $\begin{array}{l}\text { Perlakuan input receipt } \\
\text { pada proses yang tidak } \\
\text { sesuai (temperature, flow } \\
\text { rate, dll) }\end{array}$ & 4 & 5 & 160 & 3 & $\begin{array}{l}\text { Melakukan pencatatan } \\
\text { terhadap hasil sementara, } \\
\text { apabila terjadi out specs } \\
\text { segera dilakukan } \\
\text { perlakuan yang berbeda }\end{array}$ \\
\hline & & & $\begin{array}{l}\text { Penyimpanan } \\
\text { terkontaminasi } \\
\text { kotoran, suhu, dll }\end{array}$ & 1 & 1 & 8 & 6 & $\begin{array}{l}\text { Pemeriksaan } r \text { tanki } \\
\text { sebelum dan sesudah } \\
\text { digunakan }\end{array}$ \\
\hline
\end{tabular}


Tabel 5. Failure Mode Effect Analysis (lanjutan)

\begin{tabular}{|c|c|c|c|c|c|c|c|c|}
\hline $\begin{array}{c}\text { Mode } \\
\text { Kegagalan }\end{array}$ & $\begin{array}{c}\text { Efek } \\
\text { Kegagalan }\end{array}$ & $\mathbf{S}$ & Penyebab Kegagalan & 0 & D & RPN & Rank & Tindakan Perbaikan \\
\hline \multirow{5}{*}{$\begin{array}{l}\text { Nilai color } \\
\quad \text { tinggi } \\
\text { (tidak sesuai } \\
\text { spesifikasi) }\end{array}$} & \multirow{5}{*}{$\begin{array}{l}\text { RBDPO } \\
\text { berkualitas } \\
\text { rendah, tidak } \\
\text { berwarna } \\
\text { kuning jernih }\end{array}$} & \multirow{5}{*}{7} & $\begin{array}{l}\text { Operator yang tidak teliti } \\
\text { dan tidak tanggap dalam } \\
\text { melakukan pekerjaan }\end{array}$ & 4 & 6 & 168 & 2 & $\begin{array}{l}\text { Melakukan pengawasan } \\
\text { intensif terhadap kinerja } \\
\text { operator dan memberi } \\
\text { reward dan punishment } \\
\text { sesuai kinerja karyawan }\end{array}$ \\
\hline & & & $\begin{array}{l}\text { Kualitas CPO yang } \\
\text { diterima buruk akibat } \\
\text { proses pemanenan dan } \\
\text { pengolahan kelapa sawit } \\
\text { yang tidak sesuai }\end{array}$ & 7 & 7 & 343 & 1 & $\begin{array}{lr}\text { Menyeleksi CPO sesuai } \\
\text { spesifikasi } & \text { dan } \\
\text { melaporkan } & \text { kepada } \\
\text { pihak perkebunan agar } \\
\text { terjadi } \\
\text { kedepannya }\end{array}$ \\
\hline & & & $\begin{array}{l}\text { Kinerja mesin kurang } \\
\text { optimal akibat penggunaan } \\
\text { secara terus-menerus yang } \\
\text { tidak diimbangi dengan } \\
\text { perawatan }\end{array}$ & 4 & 4 & 112 & 6 & $\begin{array}{l}\text { Pemeriksaan mesin } \\
\text { secara berkala, apabila } \\
\text { terdapat kerusakan segera } \\
\text { diperbaiki }\end{array}$ \\
\hline & & & $\begin{array}{l}\text { Perlakuan input receipt } \\
\text { pada proses yang tidak } \\
\text { sesuai (persentase BE, } \\
\text { temperature, flow rate, dll) }\end{array}$ & 4 & 5 & 140 & 5 & $\begin{array}{l}\text { Melakukan pencatatan } \\
\text { terhadap hasil sementara, } \\
\text { apabila terjadi out specs } \\
\text { segera dilakukan } \\
\text { perlakuan yang berbeda }\end{array}$ \\
\hline & & & $\begin{array}{l}\text { Penyimpanan } \\
\text { terkontaminasi } \\
\text { kotoran, suhu, dll }\end{array}$ & 1 & 1 & 7 & 7 & $\begin{array}{ll}\text { Pemeriksaan } & \text { tanki } \\
\text { sebelum digunakan } & \end{array}$ \\
\hline
\end{tabular}

\section{Tahap Control}

Pada tahap ini dilakukan pemantauan terhadap perbaikan-perbaikan pada tahap improve. Pemantauan ini memastikan agar masalah yang sama tidak terulang kembali. Tahap control berfokus pada hasil RPN tertinggi dari FMEA yaitu kualitas CPO yang diterima dari perkebunan sawit buruk. Adapun pemantauan yang dilakukan berupa pembuatan Standar Operasional Prosedur (SOP) penyeleksian CPO. SOP ini dapat dijadikan sebagai pembakuan dan pedoman untuk kegiatan produksi selanjutnya. Berbeda dengan penelitian oleh (Ginting, dkk, 2018) yang hanya merekomendasikan usulan perbaikan tanpa adanya prioritas utama dan pedoman perbaikannya. Adapun prosedur penyeleksian CPO adalah:

1. Menimbang berat kotor atau gross muatan CPO yang diangkut dari pabrik perkebunan sawit melalui truk dan melakukan pencatatan yang disertai dengan jam kedatangan truk

2. Memberikan nomor antrian pada masingmasing truk

3. Mengambil sampel CPO yang diangkut oleh truk dan mengukur kualitasnya berdasarkan nilai asam lemak bebas (free fatty acid), kelembaban dan ketidakmurnian, dan indeks pemucatan atau (DOBI)

4. Melakukan pencatatan kualitas CPO dan mengklasifikasikan truk berdasarkan kualitas CPO yang diangkut.
5. Melakukan pengisian seluruh CPO ke dalam masing-masing tangki sesuai kualitasnya

6. Truk menuju jalan keluar dan menimbang tarra agar diketahui berat bersih CPO yang diangkut

7. Melakukan pencatatan berat bersih CPO disertai dengan jam keluar truk

8. Truk mengembalikan nomor antrian dan keluar dari area perusahaan

9. CPO dalam masing-masing tangki penyimpanan akan disalurkan ke tangki produksi sesuai muatan yang dibutuhkan. CPO kualitas tinggi akan diproses untuk produksi minyak goreng dan margarin, sedangkan kualitas buruk akan diproses untuk produksi lainnya seperti biodiesel

\section{KESIMPULAN}

Hasil produksi RBDPO PT XYZ dari bulan Desember 2019 hingga Januari 2020 mengalami out specs pada nilai lodine value dan color dengan nilai sigma sebesar 3,7065 dan $\mathrm{C}_{\mathrm{pk}}$ sebesar 0,7355 . Penyebab out specs adalah kurang ketelitian dan ketanggapan dari operator, kualitas CPO buruk, kinerja mesin kurang optimal, perlakuan pada proses yang tidak sesuai, dan penyimpanan minyak terkontaminasi. Usulan perbaikan dan pengendalian kualitas yang dapat dilakukan adalah seleksi pada bahan baku CPO, pengawasan intensif terhadap kinerja operator, pemeriksaan dan maintenance mesin secara berkala, pencatatan terhadap perlakuan proses 
dan hasil, serta pemeriksaan tangki penyimpanan. Penelitian lanjutan dapat dilakukan identifikasi secara mendalam mengenai kualitas produksi dari supplier.

\section{DAFTAR PUSTAKA}

Ahmed, N. G., Abohashima, H. S., \& Aly, M. F. (2018). Defect Reduction Using Six Sigma Methodology in Home Appliances Company: A Case Study. Proceedings of the International Conference on Industrial Engineering and Operations Management, 1349-1358.

http://ieomsociety.org/dc2018/papers/364.p df

Badan Pusat Statistik. (2017). Statistik Kelapa Sawit Indonesia 2017. Jakarta: Badan Pusat Statistik Indonesia. https://www.bps.go.id/publication/2018/11/1 3/b73ff9a5dc9f8d694d74635f/statistikkelapa-sawit-indonesia-2017

Fithri, P. (2019). Six Sigma Sebagai Alat Pengendalian Mutu Pada Hasil Produksi Kain Mentah Pt Unitex, Tbk.J@ti Undip: Jurnal Teknik Industri, 14(1), 43-52. https://doi.org/10.14710/jati.14.1.43-52

Gabungan Pengusaha Kelapa Sawit Indonesia. (2020). GAPKI Ramal Harga Sawit Membaik Kuartal I 2020. BPS. Jakarta. https://gapki.id/news/16030/gapki-ramalharga-sawit-membaik-kuartal-i-2020

Gaspersz, V. (2005). Total Quality Management. Jakarta: Gramedia Pustaka Utama.

Ginting, E. I., \& Ulkhaq, M. M. (2018). Analisis Pengendalian Kualitas Produksi Menggunakan Metode Six Sigma. Industrial Engineering Online Journal, 7(1), 1-10. https://ejournal3.undip.ac.id/index.php/ieoj/a rticle/view/20592

Kubiak, T. M., \& Benbow, D. W. (2016). The certified six sigma black belt handbook. Milwaukee: ASQ Quality Press.

Lestari, S. (2020). Pengendalian Kualitas Produk Compound At-807 di Plant Mixing Center dengan Metode Six Sigma Pada Perusahaan Ban di Jawa Barat. Jurnal Teknik FT UMT, 9(1), 46-52. http://jurnal.umt.ac.id/index.php/jt/article/vie w/2348

Luthfian Ramadhan Silalahi, R., Puspita Sari, D., \& Atsari Dewi, I. (2017). Testing of Free Fatty Acid (FFA) and Colour for Controlling the Quality of Cooking Oil Produced by PT. XYZ. Industria: Jurnal Teknologi Dan Manajemen Agroindustri, 6(1), 41-50. https://doi.org/10.21776/ub.industria.2017.0 06.01 .6

Manan, A., Handika, F. S., \& Nalhadi, A. (2018).
Usulan Pengendalian Kualitas Produksi Benang Carded dengan Metode Six Sigma. Jurnal INTECH Teknik Industri Universitas Serang Raya, 4(1), 38-44. https://doi.org/10.30656/intech.v4i1.856

Pangestu, P., \& Fahma, F. (2019). Implementasi Six Sigma dalam Peningkatan Kualitas Proses Produksi LED TV di PT Sharp Electronics Indonesia. Performa: Media IImiah Teknik Industri, 17(2), 152-164. https://jurnal.uns.ac.id/performa/article/view/ 30178

Rohimudin, R., Dwiputra, G. A., \& Supriyadi, S. (2016). Analisis Defect pada Hasil Pengelasan Plate Konstruksi Baja dengan Metode Six Sigma. Jurnal INTECH Teknik Industri Universitas Serang Raya, 2(1), 110.

https://ejurnal.Ippmunsera.org/index.php/INTECH/ar ticle/view/857

Sirine, H., \& Kurniawati, E. P. (2017). Pengendalian Kualitas Menggunakan Metode Six Sigma (Studi Kasus pada PT Diras Concept Sukoharjo). Asian Journal of Innovation and Entrepreneurship, 2(03), 254-290.

https://journal.uii.ac.id/ajie/article/view/8969

Stern, T. V. (2016). Lean Six Sigma: International Standards and Global Guidelines. Boca Raton: CRC Press.

Ulfah, M. (2012). Buku Panduan Magang STPK 2012 Sarjana Teknologi Pengolahan Kelapa Sawit \& Turunannya. Yogyakarta: Instiper Press.

Valles, A., Sanchez, J., Noriega, S., \& Nuñez, B. G. (2009). Implementation of Six Sigma in a manufacturing process: A case study. International Journal of Industrial Engineering, 16(3), 171-181. https://journals.sfu.ca/ijietap/index.php/ijie/a rticle/view/263

Yuanita, A. (2018). Penerapan Quality Control dengan Menggunakan Metode Six Sigma Guna Meminimalkan Produk Cacat Dalam Pembuatan Sepatu Parang Pada CV Marasabessy Bandung. Skripsi. Fakultas Ekonomi dan Bisnis Unpas Bandung. http://repository.unpas.ac.id/40807/ 